\title{
Sergančiųjų obstrukcine miego apnèja ir vaistams atsparia arterine hipertenzija apklausa
}

\author{
TELEPHONE SURVEY OF PATIENTS WITH OBSTRUCTIVE SLEEP APNEA AND DRUG \\ RESISTANT ARTERIAL HYPERTENSION
}

\author{
EGLĖ PAULAUSKAITÉ, GUODA PILKAUSKAITE் \\ LSMU MA Pulmonologijos klinika \\ Department of Pulmonology, Medical Academy, Lithuanian University of Health Sciences
}

\begin{abstract}
Santrauka. Tyrimo tikslas. Telefoninès apklausos metu įvertinti sergančiujų obstrukcine miego apnëja (OMA) ir vaistams atsparia arterine hipertenzija (AH) gydymą. Metodai. Išanalizuoti visu 2015 m. Pulmonologijos klinikos Miego laboratorijoje tirtu pacientu dokumentuoti duomenys. Atrinkti pacientai, kuriems diagnozuota vidutinio sunkumo arba sunki OMA (apnejų ir hipopnejju indeksas >15/val.), iš anamnezès žinoma, jog serga vaistams atsparia AH ir buvo rekomenduotas gydymas nuolatinio teigiamo slegio ventiliacija (angl. continuous positive airway pressure, CPAP). Atlikta atrinktu pacientu telefoninė apklausa apie OMA ir vaistams atsparios AH gydymą. Rezultatai. Itraukimo į tyrima kriterijus atitiko ir sutiko dalyvauti apklausoje 28 asmenys. Visi pacientai $(n=28)$ dèl diagnozuotos vidutinio sunkumo ir sunkios OMA gydymui miego metu naudota CPAP ventiliacija. Tyrimo metu pastebeta, kad devyniems pacientams $(32,1$ proc.) vaistams atsparios AH gydymas išliko toks pats, kaip prieš nustatant OMA ir pradedant gydyma CPAP ventiliacija, 19 pacientų (67,9 proc.) AH gydymas per ta laikotarpị buvo pakoreguotas arba sumažinus vartojamų vaistų dozę (n=8), arba nutraukus vieno iš anksčiau vartotu antihipertenzinių vaistu skyrima (n=11). Vartojamų antihipertenziniu vaistu skaičius sumažéjo tiems pacientams, kurių AHI buvo didesnis, lyginant su pacientu, kuriu vaistams atsparios AH gydymas nepakito arba buvo sumažintos vaistų dozés. Išvados. Sergančiuju OMA ir vaistams atsparia AH telefonine apklausa parode, kad, taikant gydyma CPAP ventiliacija ir kartu skiriant antihipertenzinius vaistus, pasiekta geresnè AH kontrole. Vaistams atsparios AH gydymui vartotų vaistų skaičiaus sumažinimas, taikant gydyma CPAP ventiliacija buvo pastebètas tiems OMA sergantiems pacientams, kuriu AHI buvo didesnis. Didesnès imties prospektyvieji tyrimai padèty išsiaiškinti gydymo CPAP ventiliacija nauda sergantiesiems vaistams atsparia $A H$.
\end{abstract}

Reikšminiai žodžiai: obstrukcinè miego apnejja, vaistams atspari arterinè hipertenzija, nuolatinio teigiamo slègio ventiliacija.

Summary. Objective. The aim of the telephone survey was to assess the progress of treatment in patients with obstructive sleep apnea (OSA) and drug-resistant hypertension (RH). Methods. The medical records of all patients who had a polysomnography at Pulmonology department's Sleep Laboratory in 2015 were reviewed. Study subjects were patients with RH and moderate or severe OSA (apnea-hypopnea index (AHI) >15 per hour). Results. 28 patients met the criteria and agreed to participate in the thelephone survey. All patients with OSA and RH were using CPAP therapy. The antihypertensive drug regimen was unaltered in 9 patients (32.1\%) but modifiend in 19 patients (67.9\%) by either dose reduction $(n=8)$ or by discontinuing 1 antihypertensive drug. The survey has showed that patients whose treatment was modifiend by discontinuing 1 drug had higher AHI compaired with patients whose treatment was unchanged or reduced the drug dose. Conclusions. It was noticed that CPAP therapy with antihypertensive treatment were associated with better blood pressure control in hypertensive patiens with OSA. Larger prospective trials are needed to confirm the benefit of CPAP therapy in patients with $\mathrm{RH}$.

Key words: obstructive sleep apnea, drug resistant hypertension, continuous positive airway pressure (CPAP). 


\section{Moksliniai darbai}

\section{IVADAS}

Daugiau nei 70 proc. sergančiųjų vaistams atsparia arterine hipertenzija (AH), serga ir obstrukcine miego apnèja (OMA) [1]. Literatūros duomenys, kaip gydymas nuolatinio teigiamo sleggio ventiliacija (angl. continuous positive airway pressure, CPAP) daro ittaką arterinio kraujo spaudimo (AKS) kontrolei yra prieštaringi.

OMA yra lètinè liga, pasireiškianti pasikartojančiais kvépavimo sustojimo epizodais miegant esant epizodinei hipoksijos ir miego fragmentacijai. Jos paplitimas siekia nuo 4 iki 6 proc. vidutinio amžiaus žmonių populiacijoje ir didejja priklausomai nuo amžiaus [2]. Per pastarąji dešimtmetį atlikta nemažai tyrimų, kurie parodè, kad OMA yra dažna AH priežastis ir susijusi su padidèjusia širdies ir kraujagyslių sistemos ligų rizika. Maždaug 50-56 proc. asmenų, kuriems nustatyta OMA, sirgo ir AH, o 30-40 proc. sergančiųjų AH rasta ir OMA [3].

AH yra vienas dažniausių širdies ir kraujagyslių sistemos ligų rizikos veiksnių. Net 12-27 proc. pacientų AH yra atspari medikamentiniam gydymui. Vaistams atsparia $\mathrm{AH}$ laikoma $\mathrm{AH}$, kai skiriant mažiausiai tris antihipertenzinius vaistus optimaliomis dozemis, iš kurių vienas yra diuretikas, nepavyksta pasiekti tikslinio arterinio kraujo spaudimo (AKS) $[4,5]$. Remiantis JAV arterinès hipertenzijos asociacijos gairèmis (angl. American Heart Association Guidelines) OMA yra viena dažniausių vaistams atsparios $\mathrm{AH}$ priežasčių [4]. Patogenezès mechanizmai, siejantys OMA ir AH dar nepakankamai ištirti. Manoma, kad pasikartojantys kvejpavimo sustojimai ịvyksta karu su epizodine hipoksija, tai sukelia hipoksemiją, audinių ir ląstelių hipoksiją ir sąlygoja mikroprabudimus, miego fragmentaciją. Epizodinè hipoksija sukelia simpatinès nervų sistemos aktyvaciją prabudimų metu. Dèl sumažejusio deguonies kiekio kraujyje stimuliuojami periferinių arterijų chemoreceptoriai, baroreceptoriai, didinamas simpatinès nervų sistemos aktyvumas, taip didejja arterinis kraujo spaudimas [12]. Kitas svarbus rizikos veiksnys, kuris skatina tiek vaistams atsparios AH išsivystymą, tiek OMA, yra nutukimas.

OMA gydymas, taikant CPAP ventiliaciją, laikomas patogenetiniu. Pastaraisiais metais daugeja klinikinių tyrimų, kurie nagrinejja gydymo CPAP ventiliacija reikšmę AH kontrolei. Gydymas CPAP ventiliacija slopina simpatinès nervų sistemos aktyvumą, mažina laisvųjų deguonies radikalų gamybą ir kraujagyslių endotelio disfunkciją, sukeltą OMA [10]. Gydymas CPAP ventiliacija turètu pagerinti ir AKS kontrolę pacientams, kurie serga kartu OMA ir AH. Deja, klinikinių tyrimų duomenys vis dar išlieka prieštaringi. Šio tyrimo tikslas - telefoninès apklausos metu įvertinti sergančiųjų OMA ir vaistams atsparia AH gydymą.

\section{METODIKA}

Išanalizuoti visų 2015 m. Kauno klinikų Pulmonologijos klinikos tirtų pacientų, kuriems buvo atlikta polisomnografija, duomenys. Atrinkti pacientai, kuriems buvo diagnozuota vidutinio sunkumo arba sunki OMA (apnejjų ir hipopnejų indeksas >15/val.), iš anamnezès žinoma, jog serga vaistams atsparia $\mathrm{AH}$ ir buvo rekomenduotas gydymas CPAP ventiliacija. Tiriamųjų amžius, lytis, antropometriniai duomenys: kūno masès indeksas (KMI), juosmens ir kaklo apimtys, mieguistumo įvertinimas pagal Epworth skalès rezultatus, polisomnografijos tyrimo metu nustatytas apnëjų ir hipoapnèjų indeksas (AHI), medikamentinis atsparios vaistams AH gydymas, prieš pradedant taikyti gydymą CPAP ventiliacija, buvo surinkti iš medicininès dokumentacijos. Atlikta atrinktų pacientų telefoninè apklausa apie OMA ir vaistams atsparios AH gydymą.

Duomenų analizè atlikta naudojant statistinès programos paketą „SPSS 17.0“. Dydžiai, pasiskirstę ne pagal normalujj j skirstinit, pateikiami kaip mediana (25 ir 75 procentiles). Neparametrinių kintamụjų skirtumui tarp dviejų grupių palyginti taikytas Vilkoksono (Wilcoxon) testas. Daugiau nei dviejų nepriklausomų imčių požymių skirtumui palyginti taikytas KruscallWallis testas. Reikšmingumo lygmuo, tikrinant statistines hipotezes, pasirinktas 0,05.

\section{REZULTATAI}

I tyrimą įtraukimo kriterijus atitiko 34 pacientai. Apklausoje dalyvauti sutiko 28 pacientai: 22 vyrai (79 proc.) bei 6 moterys ( 21 proc.). Iš jų 26 pacientams nustatyta sunki OMA, 2 - vidutinio sunkumo OMA. Tiriamujų charakteristikos pateikiamos 1 lentelèje.

Visi pacientai $(\mathrm{n}=28)$ del diagnozuotos vidutinio sunkumo ir sunkios OMA gydymui miego metu naudojo CPAP ventiliaciją mažiausiai 5 val. per naktị (vidutiniškai - 6-8 val.). Vartotų antihipertenzinių vaistų

1 lentelè. Sergančiujų obstrukcine miego apnèja ir vaistams atsparia arterine hipertenzija charakteristikos

\begin{tabular}{|l|c|}
\hline Požymis & Duomenys \\
\hline Amžius, metai & $60(54-69)$ \\
\hline KMI, kg/m² & $41,32(35,69-47,13)$ \\
\hline Liemens apimtis, cm & $130(117-136)$ \\
\hline Kaklo apimtis, cm & $45(43-50)$ \\
\hline $\begin{array}{l}\text { Epworth mieguistumo skalè, } \\
\text { balai }\end{array}$ & $9(5-15,50)$ \\
\hline AHI, kvejpavimo ivykiai/val. & $70,85(39,65-85,85)$ \\
\hline Antihipertenziniai vaistai, $n$ & $4(3-5)$ \\
\hline
\end{tabular}

$\mathrm{KMI}$ - kūno masès indeksas; AHI - apnejjų hipopnèjų indeksas; duomenys pateikiami kaip mediana ( 25 ir 75 procentilès). 


\section{Moksliniai darbai}

2 lentelè. Sergančiujų obstrukcine miego apnèja ir vaistams atsparia arterine hipertenzija antropometrinių duomenų ir obstrukcinès miego apnèjos sunkumo rodiklių palyginimas

\begin{tabular}{|l|c|c|c|c|}
\hline Požymis & $\begin{array}{l}\text { Antihipertenzinių } \\
\text { vaistų vartojimas } \\
\text { nepakito (1 grupé) }\end{array}$ & $\begin{array}{l}\text { Sumažejo vartojamų } \\
\text { antihipertenzinių } \\
\text { vaistų dozé (2 grupé) }\end{array}$ & $\begin{array}{l}\text { Sumažejo vartojamų } \\
\text { antihipertenzinių vaistų } \\
\text { skaičius (3 grupė) }\end{array}$ & $\mathbf{p}$ \\
\hline Amžius, metai & $64(52-70)$ & $50(57-71)$ & $60(55-68)$ & 0,87 \\
\hline KMI, kg/m² & $37,4(31,95-46,43)$ & $43,16(38,34-49,13)$ & $41,96(36,23-47,34)$ & 0,33 \\
\hline Kaklo apimtis, cm & $45(43-46)^{*}$ & $49(46-53)^{*}$ & $45(41-50)$ & 0,15 \\
\hline Liemens apimtis, cm & $130(117-137)$ & $133(118-148)$ & $131(121-135)$ & 0,55 \\
\hline AHI, ivykių/val. & $39,6(26-71,15) \S$ & $78,15(37,92-84,85)$ & $85,90(59,40-94,60) \S$ & 0,13 \\
\hline Epworth mieguistumo skalè, balai & $6(5-15,5)$ & $12(4,5-19,75)$ & $10(6-14)$ & 0,52 \\
\hline
\end{tabular}

Duomenys pateikiami kaip mediana ( 25 ir 75 procentilès); Kruscal Wallis testas; ${ }^{*}-p<0,05$ palyginus 1 ir 2 grupę, ${ }^{\S}-p<0,05$ palyginus 1 ir 3 grupę, reikšmingu skirtumų tarp 2 ir 3 grupių nerasta.

skaičius reikšmingai sumažèjo taikant gydymą CPAP ventiliacija (Wilcoxon testas, $\mathrm{p}=0,001$ ). Tyrimo metu pastebèta, kad devyniems pacientams (32,1 proc.) vaistams atsparios AH gydymas išliko toks pats kaip ir prieš nustatant OMA ir pradedant gydymą CPAP ventiliacija, 19 pacientų (67,9 proc.) AH gydymas per tą laikotarpi buvo pakoreguotas arba sumažinus vartojamų vaistų dozę $(n=8)$, arba nutraukus vieno iš anksčiau vartotų antihipertenzinių vaistų skyrimą $(\mathrm{n}=11)$. Siekiant išsiaiškinti, kuo skiriasi pacientai, kuriems buvo pakoreguotas $\mathrm{AH}$ gydymas, atliktas tiriamųjų amžiaus, antropometrinių duomenų ir OMA sunkumo rodiklių palyginimas, suskirsčius pacientus $\mathfrak{i}$ tris grupes pagal antihipertenzinių vaistų vartojimo pokyti (2 lentelè).

\section{DISKUSIJA}

Ši telefoninė apklausa parodė, kad sergančiųjų vidutinio sunkumo ir sunkia OMA gydymas CPAP ventiliacija gali pagerinti vaistams atsparios $\mathrm{AH}$ kontrolę. Tyrimo metu išnagrinèti visų $2015 \mathrm{~m}$. Pulmonologijos klinikos Miego laboratorijoje tirtų pacientų medicininès dokumentacijos duomenys. Bandyta apklausti visus pacientus, atitinkančius vidutinio sunkumo ir sunkios OMA ir vaistams atsparios AH kriterijus, bet šeši pacientai atsisakè dalyvauti apklausoje, taigi atsakomumas siekè 82,4 proc. Buvo vertinamas vartojamų antihipertenzinių vaistų skaičius, jų dozės ir AKS kontrole prieš pradedant gydymą CPAP ventiliacija ir praejjus maždaug vieneriems metams. Rezultatai parodę, kad 67,9 proc. pacientų ( $n=19$ iš 28$)$ buvo koreguotas antihipertenzinis gydymas sumažinant vaistų dozę arba nutraukiant vieno iš antihipertenzinio vaistų skyrimą, rodo, jog OMA ilgalaikis gydymas CPAP ventiliacija turi teigiamą poveikį ir vaistams atsparios AH gydymui bei geresnei jos kontrolei.

Kliniškai įrodyta, kad OMA - vienas iš rizikos veiksnių, sąlygojančių $\mathrm{AH}$ atsiradimą ir blogesnius jos gydymo rezultatus $[5,7,8]$. Atlikta keletas klinikinių tyrimų, kurie vertino gydymo CPAP ventiliacija poveiki AKS sergantiesiems OMA. Pastebèta, kad gydymas CPAP ventiliacija padeda sumažinti AKS ir dienos, ir nakties metu pacientams, kuriems diagnozuota OMA [10]. Tarptautinès arterinès hipertenzijos gairès rodo, jog net minimalus arterinio kraujo spaudimo sumažèjimas (2-3 mm Hg st. sistolinio AKS) gali turèti didelę klinikinę reikšmę širdies ir kraujagyslių sistemos ligų rizikai ir mirštamumo nuo jų sumažejjimui [9]. Vidutinio AKS sumažẻjimas nuo 5 iki 10 proc. AH sergantiems pacientams gali sumažinti infarkto riziką net iki 40 proc. [9]. Iki šiol tik keli klinikiniai tyrimai vertino CPAP ventiliacijos reikšmę gydant OMA ir vaistams atsparia AH sergančius pacientus. Pastebètas kliniškai reikšmingas AKS sumažèjimas, ypač nakties metu ir būtent tiems pacientams, kurie gerai toleravo gydymą CPAP. Pastebèta, jog gydomasis poveikis yra tada, kai gydymas CPAP ventiliacija naudojamas ne mažiau kaip 4 val. per naktị [9]. Šiuos rezultatus pagrindè ir iki šiol bene didžiausios imties klinikinis tyrimas HIPARCO [10]. Tai daugiacentris tyrimas, kurio metu i tyrimą itraukti 194 pacientai, kurie sirgo vaistams atsparia AH ir OMA. Pastebèta, kad, taikant gydymą CPAP ventiliacija ir medikamentinị AH gydymą, sumažejo vidutinis ir diastolinis AKS, lyginant su kontroline grupe, kai buvo skirtas tik medikamentinis AH gydymas.

Šio tyrimo duomenimis, vartojamų antihipertenzinių vaistų skaičius sumažèjo tiems pacientams, kurių AHI buvo didesnis, lyginant su pacientų, kurių vaistams atsparios AH gydymas nepakito arba buvo sumažintos vaistų dozès. KMI ir liemens apimties skirtumų tiriamujų, kuriems koreguotas ir nekoreguotas gydymas antihipertenziniais vaistais, nebuvo, nors kaklo apimtis buvo didesnè pacientų, kuriems sumažèjo vartojamų antihipertenzinių vaistų dozé, taikant gydymą CPAP ventiliacija. Neturime paaiškinimo, kodèl šie skirtumai išryškejjo, nors literatūroje yra duomenų apie skysčių 


\section{Moksliniai darbai}

pasiskirstymo organizme svarbą OMA sunkumui, ypač miego metu gulint horizontalioje padètyje. Nutukimo itaka OMA ir vaistams atsparios AH išsivystyme jau nagrinètas ne viename tyrime ir įrodytas patogenetiniu mechanizmų persidengimas [11]. Taigi planuojant tolesnius tyrimus, būtina vertinti ir antropometrinių rodikliu dinamiką.

Šiame tyrime tiriamieji teigè, kad gydymą CPAP ventiliacija toleravo gerai ir naudojo daugiau nei 4 val. miego metu. Šio tyrimo trūkumai buvo maža tiriamųjų imtis ir tai, jog ilgalaikis gydymo CPAP ventiliacija poveikis AKS nebuvo vertinamas atliekant 24 val. AKS stebėseną, kaip tą rekomenduoja Amerikos širdies asociacijos gairès [10]. Nebuvo objektyvizuota gydymo CPAP ventiliacija trukmè, nes ji vertinta tik klausiant tiriamųjų, kiek vidutiniškai valandų per naktį naudoja CPAP ventiliaciją. Be to, šioje apklausoje nebuvo jokių kriterijų, kurie padètu ìvertinti CPAP ventiliacijos kokybę. Ši apklausa yra pilotinis tyrimas prieš numatomą prospektyvųjį tyrimą, kurio metu bus tiriama gydymo CPAP įtaka sergant sisteminėmis ir plaučių kraujagyslių ligomis. Planuojamo tyrimo metu būtina vertinti CPAP ventiliacijos trukmę ir kokybę pagal CPAP ventiliatorių atminties laikmenose fiksuojamus duomenis, rodančius ventiliacijos naudojimo trukmę, išliekančius kvėpavimo įvykius bei oro srovès nuotèkius.

\section{IŠVADOS}

Sergančiųjų OMA ir vaistams atsparia AH telefonine apklausa parodè, kad taikant gydymą CPAP ventiliacija ir kartu skiriant antihipertenzinius vaistus, pasiekta geresnè AH kontrolè, tai rodo mažesnių vaistų dozių arba vartojamų antihipertenzinių vaistų skaičiaus poreikis. Vaistams atsparios AH gydymui vartotų vaistų skaičiaus sumažinimas, taikant gydymą CPAP ventiliaciją pastebètas tiems sergantiesiems OMA, kurių AHI buvo didesnis. Didesnès imties prospektyvieji tyrimai padètų išsiaiškinti gydymo CPAP ventiliacija naudą sergantiesiems vaistams atsparia $\mathrm{AH}$.

\section{LITERATŪRA}

1. Logan AG, Perlikowski SM, Mente A, Tisler A, Tkacova R, Niroumand $\mathbf{M}$, et al. High prevalence of unrecognized sleep apnea in drug-resistant hypertension. J Hypertens. 2001; 19(12):2271-7.

2. Durịn J, Esnaola S, Rubio R, Iztueta A. Obstructive sleep apnea-hypopnea and related clinical features in a populationbased sample of subjects aged 30 to 70 years. Am J Respir Crit Care Med. 2001; 163(3 Pt 1):685-9.

3. Chobanian AV, Bakris GL, Black HR, Cushman WC, Green LA, Izzo JL Jr, et al.; Joint National Committee on Prevention, Detection, Evaluation, and Treatment of High Blood Pressure, National Heart, Lung, and Blood Institute; National High Blood Pressure Education Program Coordinating Committee. Seventh report of the Joint National Committee on Prevention, Detection, Evaluation, and Treatment of High Blood Pressure. Hypertension. 2003; 42(6):1206-52.

4. Persell SD. Prevalence of resistant hypertension in the United States, 2003-2008. Hypertension. 2011; 57(6):1076-80.

5. de la Sierra A, Segura J, Banegas JR, Gorostidi M, de la Cruz JJ, Armario P, et al. Clinical features of 8295 patients with resistant hypertension classified on the basis of ambulatory blood pressure monitoring. Hypertension. 2011; 57(5):898-902.

6. Mancia G, De Backer G, Dominiczak A, Cifkova R, Fagard R, Germano G, et al.; ESH-ESC Task Force on the Management of Arterial Hypertension. 2007 ESH-ESC Practice Guidelines for the Management of Arterial Hypertension: ESH-ESC Task Force on the Management of Arterial Hypertension. J Hypertens. 2007; 25(9):1751-62.

7. Calhoun DA, Jones D, Textor S, Goff DC, Murphy TP, Toto RD, et al. Resistant hypertension: diagnosis, evaluation, and treatment. A scientific statement from the American Heart Association Professional Education Committee of the Council for High Blood Pressure Research. Hypertension. 2008; 51(6):1403-19.

8. Martķnez-Garcka MA, Capote F, Campos-Rodrksguez F, Lloberes P, Díaz de Atauri MJ, Somoza M, et al. Effect of CPAP on blood pressure in patients with obstructive sleep apnea and resistant hypertension the HIPARCO randomized clinical trial. JAMA. 2013; 310(22):2407-15.

9. Montesi SB, Edwards BA, Malhotra A, Bakker JP. The effect of continuous positive airway pressure treatment on blood pressure: a systematic review and meta-analysis of randomized controlled trials. J Clin Sleep Med. 2012; 8(5):587-96.

10. Dernaika TA, Kinasewitz GT, Tawk MM. Effects of nocturnal continuous positive airway pressure therapy in patients with resistant hypertension and obstructive sleep apnea. J Clin Sleep Med. 2009; 5(2):103-7.

11. Marcus JA, Pothineni A, Marcus CZ, Bisognano JD. The role of obesity and obstructive sleep apnea in the pathogenesis and treatment of resistant hypertension. Curr Hypertens Rep. $2014 ; 16(1): 411$.

12. Lozano L, Tovar JL, Sampol G, Romero O, Jurado MJ, Segarra A, et al. Continuous positive airway pressure treatment in sleep apnea patients with resistant hypertension: a randomized, controlled trial. J Hypertens. 2010; 28(10):2161-8. 